Article

\title{
Droplet-Assisted Laser Direct Nanoscale Writing on Silicon ${ }^{\dagger}$
}

\author{
Yuan-Jen Chang ${ }^{1, *} \ddagger$, Chao-Hsuan Chang ${ }^{1, \ddagger}$, Chao-Ching Ho ${ }^{2}$, Jin-Chen Hsu ${ }^{1}$ and \\ Chia-Lung Kuo ${ }^{1}$ \\ 1 Department of Mechanical Engineering, National Yunlin University of Science and Technology, Douliou, \\ Yunlin 640, Taiwan; u9711012@yuntech.edu.tw (C.-H.C.); hsujc@yuntech.edu.tw (J.-C.H.); \\ kuocl@yuntech.edu.tw (C.-L.K.) \\ 2 Department of Mechanical Engineering, National Taipei University of Technology, Taipei 106, Taiwan; \\ hochao@mail.ntut.edu.tw \\ * Correspondence: changy@yuntech.edu.tw; Tel.: +886-5-5342601 (ext. 4129) \\ $+\quad$ This is an extended version of conference paper published in IEEE-NEMS 2014. \\ $\ddagger$ These authors contributed equally to this work.
}

Academic Editor: Manoj Gupta

Received: 31 December 2015; Accepted: 19 February 2016; Published: 2 March 2016

\begin{abstract}
Nano-structuring using laser direct writing technology has shown great potential for industrial applications. A novel application of water droplets to this technology is proposed in this paper. With a hydrophobic layer and a controlled substrate temperature, a layer of randomly distributed water droplets with a high contact angle is formed on the substrate. These liquid droplets can be used as lenses to enhance the laser intensity at the bottom of the droplets. As a result, nanoscale holes can be fabricated on the substrate by controlling the laser energy density. We successfully fabricated holes with a diameter of $600 \mathrm{~nm}$ at a substrate temperature of $12{ }^{\circ} \mathrm{C}$ and a power density of $1.2 \times 10^{8} \mathrm{~W} / \mathrm{cm}^{2}$ in our experiments. We also found that the hole diameter was around a ninth of the water droplet diameter. Meanwhile, the machined holes are not affected much by the focal length of the lens, but a hole with less than $100 \mathrm{~nm}$ in diameter at the center was observed.
\end{abstract}

Keywords: direct writing; laser; droplet; nanoscale

\section{Introduction}

Nanoscale manufacturing technology has been widely applied in the areas of integrated circuits [1], hard disks [2], flexible electronics [3], and optoelectronics [4,5]. However, the cost of conventional optical nanolithography is extremely high. The next-generation nanofabrication techniques still have disadvantages, such as the low throughput of e-beam lithography, and the reliance of the mold fabrication of nanoimprinting on conventional nanolithography. One laser direct writing nanolithography technology is achieved by near-field optics, and three major methods have been developed recently. Laser nanolithography uses a semiconductor, metallic nanoparticles, or a tip-based microscope to enhance the laser intensity directly beneath the particles or tips [6]; however, they have their own technical barriers. In tip-based near-field laser nanolithography, the tip is easily damaged [7], and the throughput is still low [8]. By applying micro/nanoscale spherical particles, the flexibility of the pattern design is limited and the particles are one-time use only. Although different incident angles of the laser increase the time of use of each micro/nanoparticle, the reliability and the uniformity still need to be improved $[9,10]$. Another method to apply near-field laser direct writing lithography is optical trapping technology, in which particles are moved around on the surface of the substrates [11,12]. The lifetime of the particles is extended by keeping them a tiny distance from the substrate. However, with optical trapping technology, the parallel control of multiple particles is 
complicated. A novel application of liquid droplets to enhance the laser intensity was investigated in this study. The droplets could be formed and removed easily. Moreover, the droplets instantly cooled down the ablation spots and helped remove the debris during the process. In this study, our intention was to demonstrate the potential of using liquid droplets in laser direct writing nanofabrication. With the condensation of water on silicon in air, the droplets could be randomly distributed on the silicon substrate; therefore, the machined holes were randomly distributed as well. By carefully controlling the laser power density, the debris around the machined holes could be minimized.

\section{Principle}

The liquid droplet acts as a lens to refract the laser beam, as shown in Figure 1. With a higher refractive index than air, the laser beam is focused onto the substrate. The curvature of the droplet depends on both the contact angle of the droplet, $\theta$, as well as the diameter of the droplet. With a larger curvature, the radius of the beam focused onto the substrate is smaller. In order to minimize the radius of the beam, a larger droplet contact angle and a smaller volume of the droplet are preferable. When the laser beam is focused onto the substrate, laser ablation occurs if the energy density reaches the threshold ablation energy density of the silicon. Taking advantage of the Gaussian distribution of a laser beam, the threshold energy density can be adjusted to be reached in a small area at the center part of the laser beam. Thereby, a nanoscale silicon hole by laser ablation is obtained.

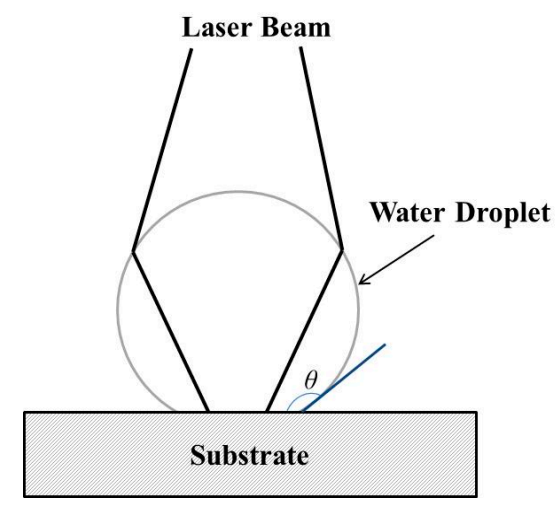

Figure 1. Schematic view of laser direct nano-structuring technology.

\section{Materials and Methods}

A schematic of the experimental setup is shown in Figure 2. Silicon (Hsin-Chu, Taiwan) coated with a hydrophobic layer was the substrate for patterning. The hydrophobic layer, 1H-1H-2H-2H-Perfluorooctyl-trichlorosilane, was deposited on the silicon substrate by vapor deposition. The substrate was then placed on a thermoelectric cooler (TEC), and the temperature of the silicon was manually controlled with a DC power supply. A pulsed Nd-YAG laser (Lotis TII, Japan) with a wavelength of $532 \mathrm{~nm}$ was utilized due to the high absorption by silicon [13] and the low absorption by water [14]. The pulse duration was $6 \mathrm{~ns}$ while the output beam size was $6.3 \mathrm{~mm}$ in diameter. After being reflected by the first mirror, the laser beam passed through three neutral density filters with different optical density (OD) numbers, $0.2,0.3$, and 1.0, in a series. The laser beam was positively defocused with respect to the substrate, i.e. the focal point was above the substrate and the water droplets. The focal length of the lens was $83.8 \mathrm{~mm}$. The TEC and the silicon substrate were placed on a block of aluminum with a thin layer of thermal paste for heat dissipation. The whole setup was then placed on the stage of a Sodick AP1L Micro Precision Electrical Dischage Machining (EDM) machine (Sodick, Japan). A zoom lens with a charge-coupled device (CCD) was set to take an in situ image of droplets while the silicon substrate was cooling. The image was taken first, and the substrate was moved to the designated position under the lens within $6 \mathrm{~s}$ afterwards. A picture of the setup is shown in Figure 3. 


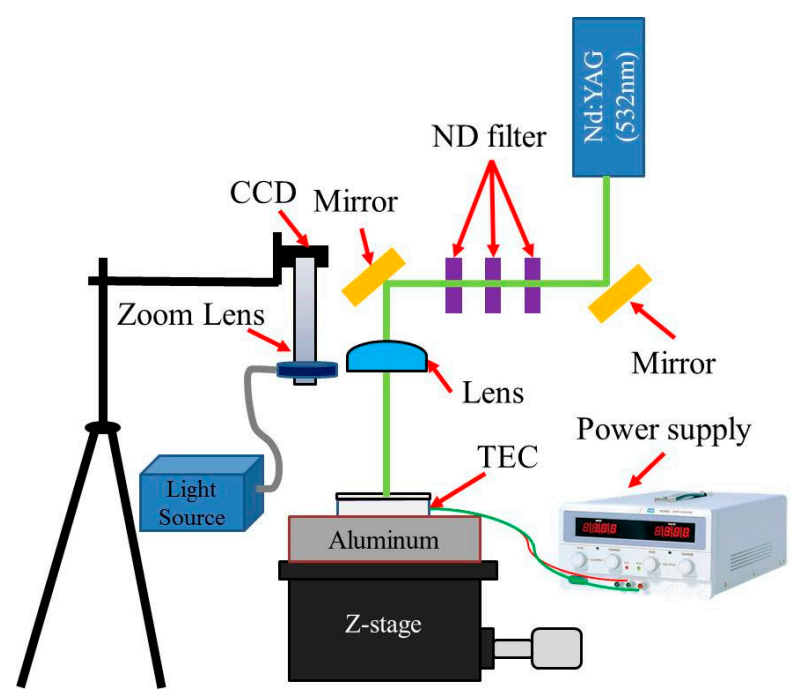

Figure 2. Schematic view of the experimental setup.

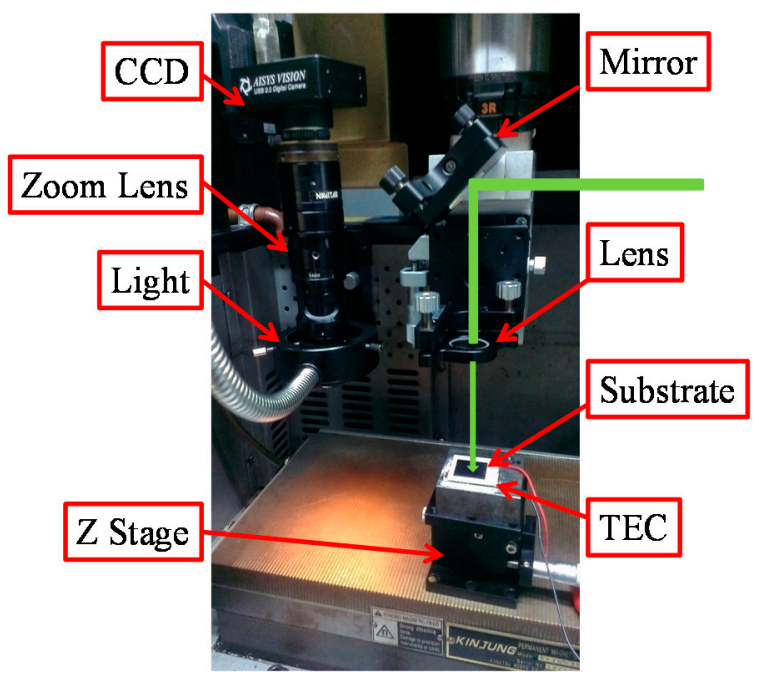

Figure 3. Picture of the experimental setup.

\section{Results and Discussion}

When the substrate temperature was below $12{ }^{\circ} \mathrm{C}$, the water droplets were randomly condensed on the silicon, while the relative humidity was in the normal range of $55 \%$ to $45 \%$. We measured the size of droplets from 1 to $7 \mathrm{~min}$ after reaching the designated substrate temperature. The observed results are shown in Figure 4. The size of the droplets increased with time and decreased with temperature. We further reduced the condensation time to $20 \mathrm{~s}$ and $30 \mathrm{~s}$ at both $10^{\circ} \mathrm{C}$ and $12{ }^{\circ} \mathrm{C}$. A picture of the condensed water droplets distributed randomly on the silicon is shown in Figure 5. The diameter in pixels was measured manually for each droplet with the scale bar for obtaining size distribution, as shown in Figure 6. Five different positions on the substrate were measured, including the center and the four corners of the substrate. The droplet diameter distributions are shown in Figure 7. The range of the droplet diameter was $13 \mu \mathrm{m}$ to $22 \mu \mathrm{m}$, depending on the temperature and the condensing time. The variation in diameter at each temperature was around $4 \mu \mathrm{m}$. The results also showed that the droplet diameter distribution at $10^{\circ} \mathrm{C}$ for $30 \mathrm{~s}$ was similar to that at $12{ }^{\circ} \mathrm{C}$ for $20 \mathrm{~s}$. The contact angle of the droplet on the hydrophobic surface was measured to be $\sim 126^{\circ}$ by a contact angle analyzer (Phoenix 150, SEO, Korea), as shown in Figure 8. 


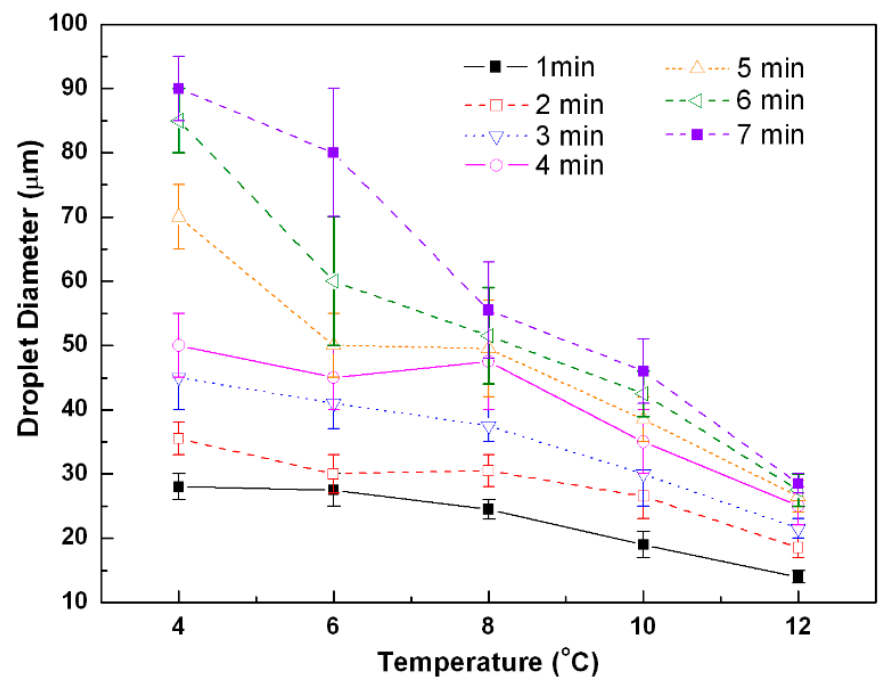

Figure 4. The diameter of droplets on silicon changed with substrate temperature and with the time after reaching the designated temperatures.

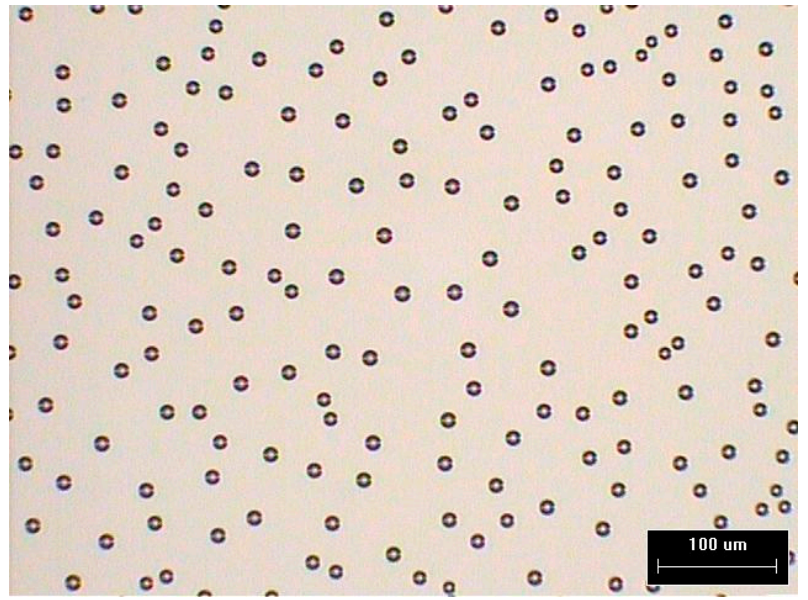

Figure 5. OM picture of condensed water droplet on silicon at $12{ }^{\circ} \mathrm{C}$ for $20 \mathrm{~s}$.

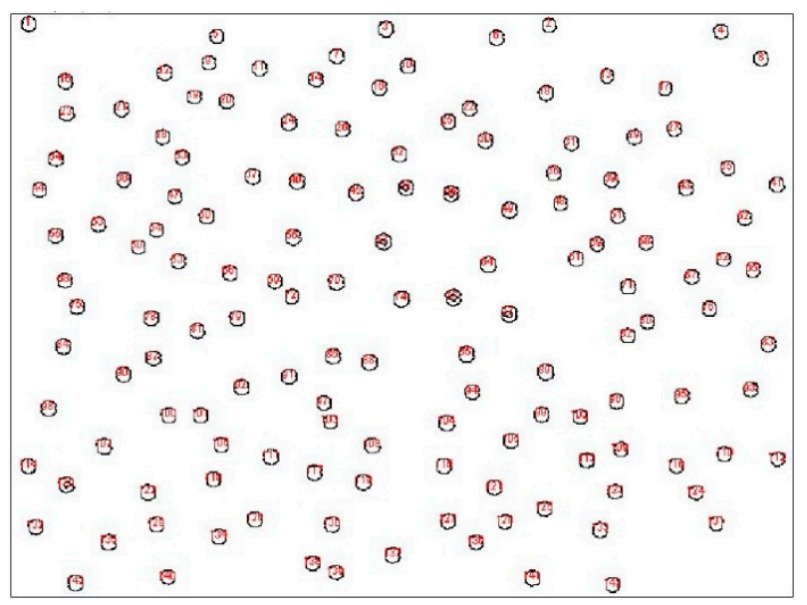

Figure 6. Binary image of condensed water droplet on silicon at $12{ }^{\circ} \mathrm{C}$ for $20 \mathrm{~s}$. 


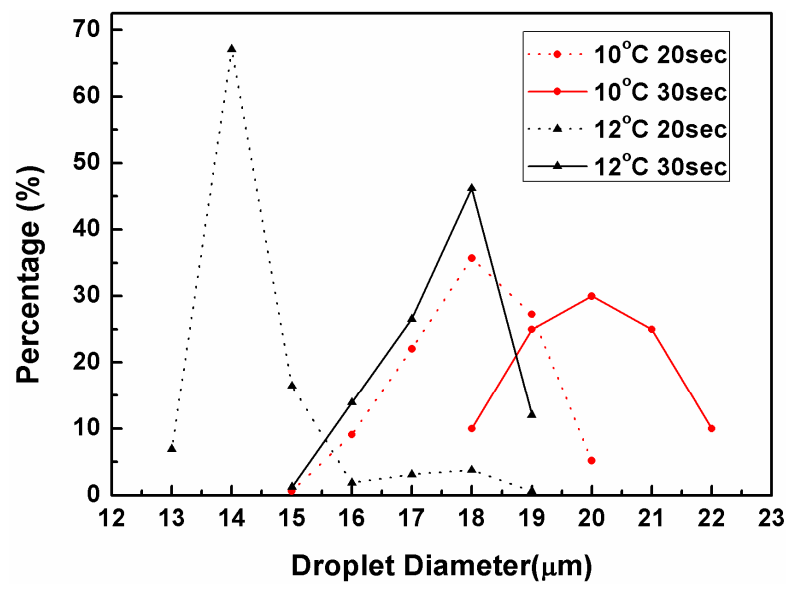

Figure 7. Size distribution of droplets at $10{ }^{\circ} \mathrm{C}$ and $12{ }^{\circ} \mathrm{C}$.

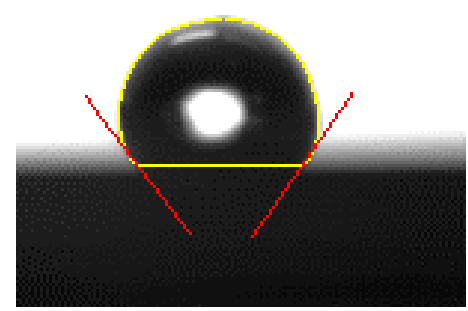

Figure 8. Contact angle measurement result.

The laser radiation power after passing through the neutral density filters was $41 \mathrm{~mW}$, with a pumping energy of 23 Joules. Four different power densities were used in our experiments: $1.9 \times 10^{8}$, $1.6 \times 10^{8}, 1.4 \times 10^{8}$, and $1.2 \times 10^{8} \mathrm{~W} / \mathrm{cm}^{2}$, and were achieved by adjusting the defocusing distance. The scanning electron microscope (SEM) pictures of the machined holes at different power densities with a substrate temperature of $12{ }^{\circ} \mathrm{C}$ are shown in Figure 9. From the pictures, we found that the machined area was increased with laser intensity. It can be seen that the holes still exist in the lower left part of the machined area with the lowest power density. This indicates the power density distribution in the laser beam. Higher laser intensity produced the melted silicon sputtered around the hole, while lower laser intensity fabricated circular melting zones, as shown in Figure 9. In Figure 9a, different shapes of holes represent the local power density distribution of the laser beam. With the lowest power density of $1.2 \times 10^{8} \mathrm{~W} / \mathrm{cm}^{2}$ in our experiments, it can be seen in an enlarged image of Figure $9 \mathrm{~d}$ that the hole shapes were all circular with less silicon debris surrounding the holes, as shown in Figure 10. With the local power density slightly over the silicon damage threshold, the minimum hole size could be obtained.

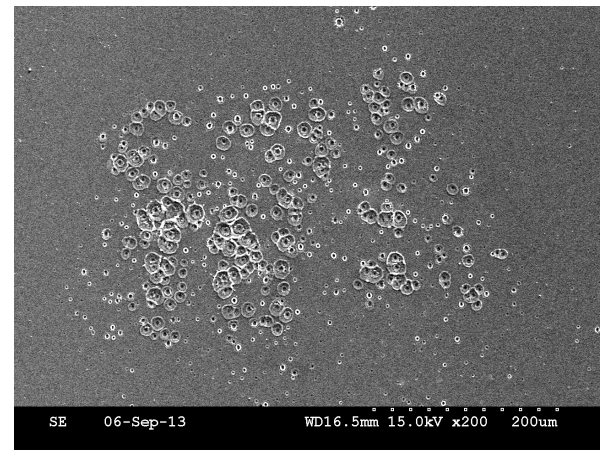

(a) $1.9 \times 10^{8} \mathrm{~W} / \mathrm{cm}^{2}$

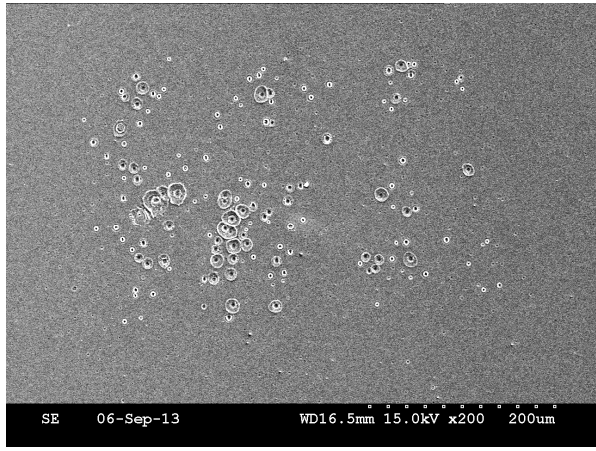

(b) $1.6 \times 10^{8} \mathrm{~W} / \mathrm{cm}^{2}$

Figure 9. Cont. 


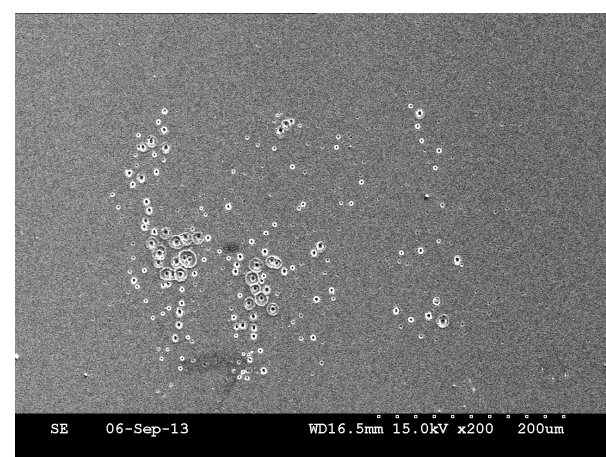

(c) $1.4 \times 10^{8} \mathrm{~W} / \mathrm{cm}^{2}$

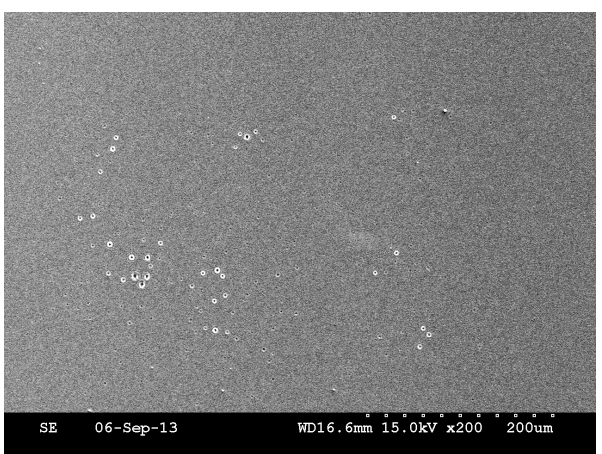

(d) $1.2 \times 10^{8} \mathrm{~W} / \mathrm{cm}^{2}$

Figure 9. SEM pictures of machined holes at different laser power densities $\left(12{ }^{\circ} \mathrm{C}\right.$ for $\left.20 \mathrm{~s}\right)$.

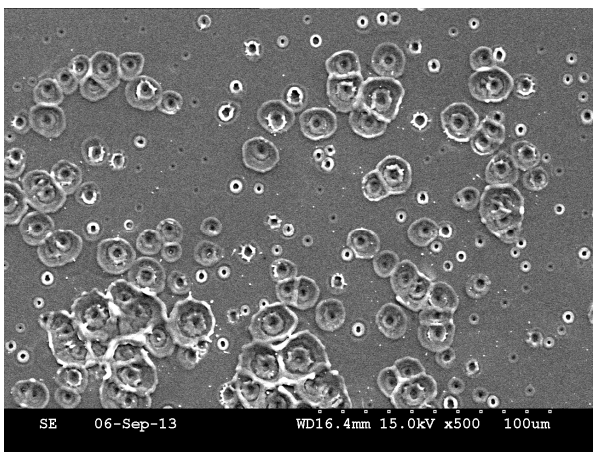

(a) $1.9 \times 10^{8} \mathrm{~W} / \mathrm{cm}^{2}$

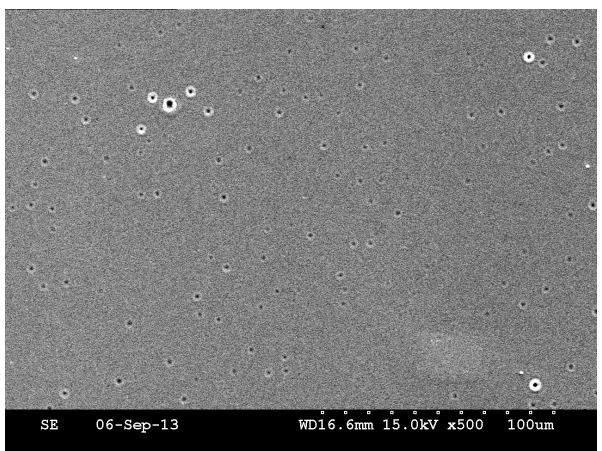

(b) $1.2 \times 10^{8} \mathrm{~W} / \mathrm{cm}^{2}$

Figure 10. Enlarged SEM pictures of machined holes with $12{ }^{\circ} \mathrm{C}$ for $20 \mathrm{~s}$.

Since the machined holes were all perfectly circular with a power density of $1.2 \times 10^{8} \mathrm{~W} / \mathrm{cm}^{2}$, we measured the width of the melting area and the diameter of the holes machined at this specific power density. An example of the measured hole is shown in Figure 11. The size distribution of the melting zone and the diameter of the machined holes were measured, and the results are shown in Figures 12 and 13 respectively. The diameter of the melting zone, i.e., the outer diameter of the melting silicon area, was $3 \mu \mathrm{m}$ to $7.2 \mu \mathrm{m}$. The diameter range of the machined hole at the center was $0.6 \mu \mathrm{m}$ to $4 \mu \mathrm{m}$. Lower temperatures and longer condensing times produced larger machined holes. The results also showed that the melting areas of the machined holes were all around $30 \%$ of the diameter of the water droplets at the corresponding temperatures and condensation times, as shown in Figure 14. This showed that the power density area in a focused Guassian beam through the liquid lens possibly corresponded to the silicon damage threshold.

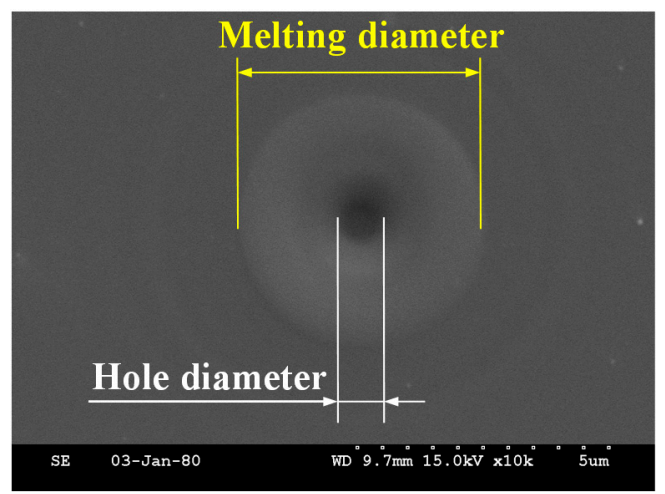

Figure 11. SEM picture of a machined hole with power density of $1.2 \times 10^{8} \mathrm{~W} / \mathrm{cm}^{2}$ at $12{ }^{\circ} \mathrm{C}$ for $20 \mathrm{~s}$. 


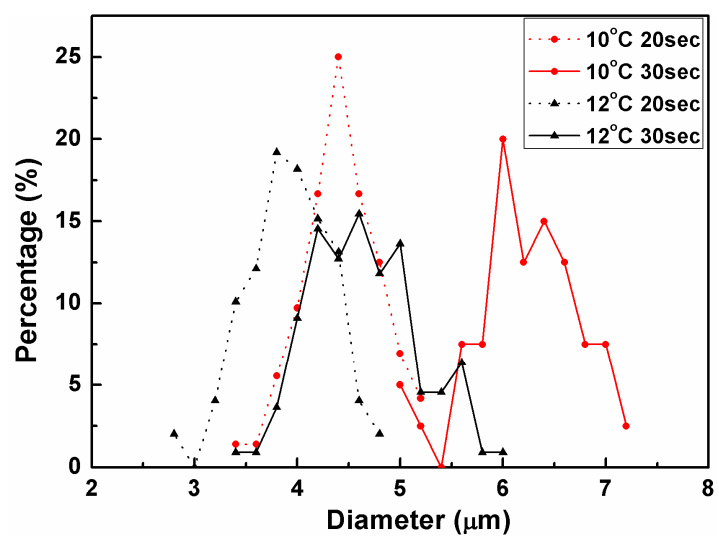

Figure 12. Size distribution of melting width of machined holes at $10{ }^{\circ} \mathrm{C}$ and $12{ }^{\circ} \mathrm{C}$ with a power density of $1.2 \times 10^{8} \mathrm{~W} / \mathrm{cm}^{2}$.

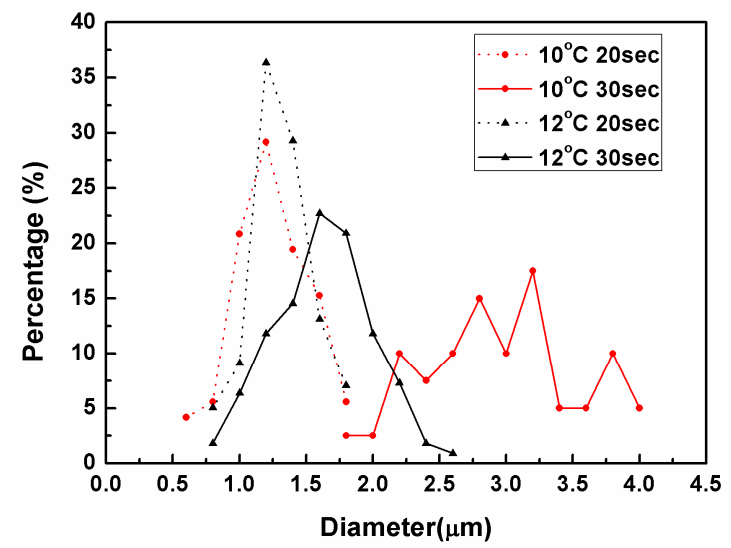

Figure 13. Diameter distribution of machined holes at $10{ }^{\circ} \mathrm{C}$ and $12{ }^{\circ} \mathrm{C}$ with a power density of $1.2 \times 10^{8} \mathrm{~W} / \mathrm{cm}^{2}$.

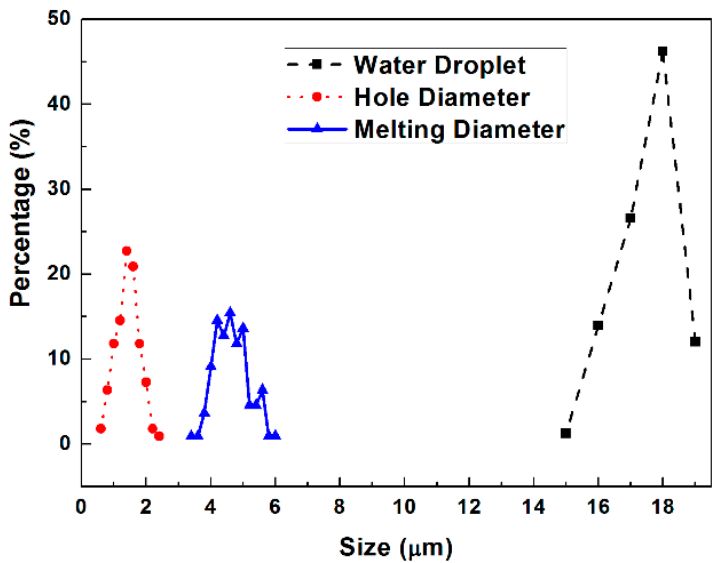

Figure 14. Comparison of droplet size, hole diameter and melting diameter of machined holes at $12{ }^{\circ} \mathrm{C}$ condensing for $30 \mathrm{~s}$.

We also compared the hole diameters with water droplet size at different designated temperatures, and the results are shown in Figure 15. The power density was $1.88 \times 10^{8} \mathrm{~W} / \mathrm{cm}^{2}$. In these experiments, we fabricated the holes on the substrate after $1 \mathrm{~min}$ when the designated temperature of silicon was reached. The temperature ranged from $6{ }^{\circ} \mathrm{C}$ to $12{ }^{\circ} \mathrm{C}$. The size of the holes were measured with an 
SEM. We observed that the higher the substrate temperature that we applied, the smaller the hole diameter that we obtained. The results also show that the smaller droplet size generates smaller holes. Smaller droplets provide larger curvature and results in smaller spot by refraction in the droplet. We also observed that the hole diameters were around a third of the diameter of droplets.

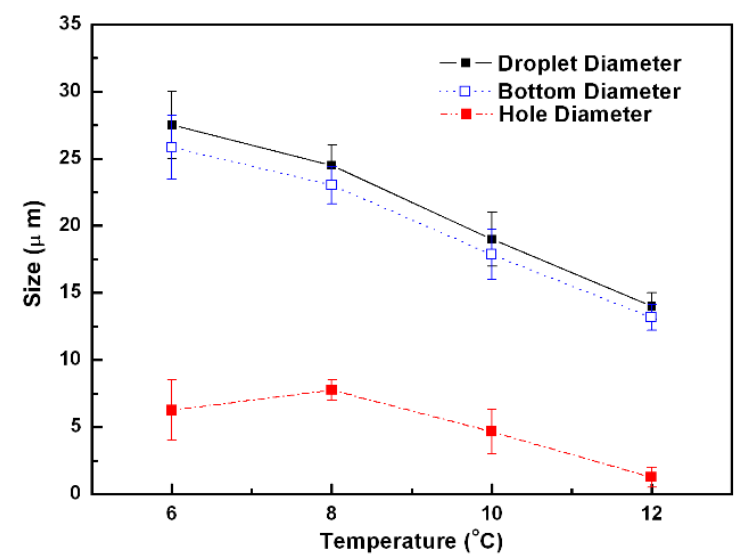

Figure 15. Comparisons among droplet diameters, bottom diameters of droplets, and fabricated hole diameters, with the substrate temperature ranging from $6{ }^{\circ} \mathrm{C}$ to $12{ }^{\circ} \mathrm{C}$.

Moreover, we compared the fabricated holes with different focal lengths, including $56 \mathrm{~mm}$, $83.8 \mathrm{~mm}$, and $111.8 \mathrm{~mm}$. The results are shown in Figure 16. The power density used in these experiments was $1.5 \times 10^{8} \mathrm{~W} / \mathrm{cm}^{2}$. From the SEM pictures, ultra-small holes were found at the center of machined holes. The size of the holes was less than $100 \mathrm{~nm}$. We suggest that it was due to the concentrated energy of a Gaussian laser beam.

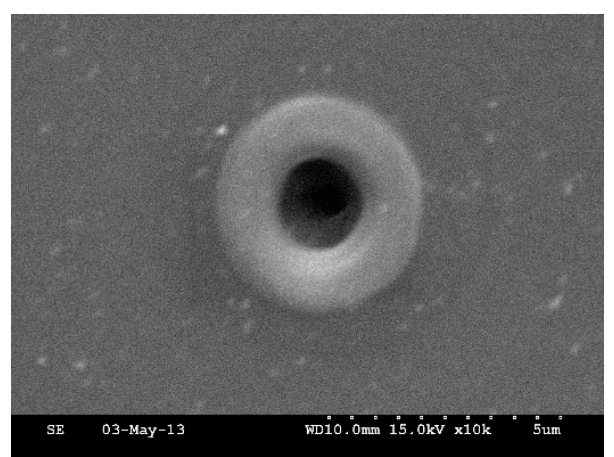

(a) Focal length $=56 \mathrm{~mm}$

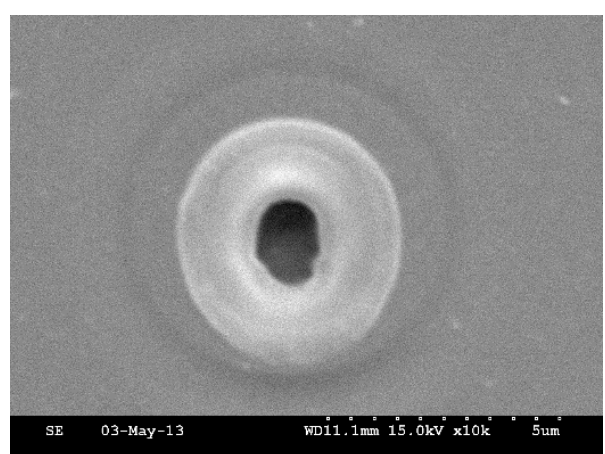

(b) Focal length $=83.8 \mathrm{~mm}$

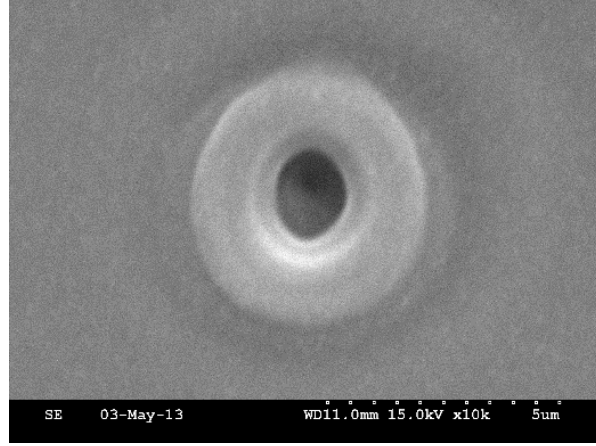

(c) Focal length $=111.8 \mathrm{~mm}$

Figure 16. SEM picture of machined holes with different focal length (scale bar $=5 \mu \mathrm{m}$ ). 
We reduced the power density to $1.0 \times 10^{8} \mathrm{~W} / \mathrm{cm}^{2}$, and the machined holes with different focal lengths are shown in Figure 17. It was clearly found that the ultra-small hole at the center disappeared with the focal lengths of $83.8 \mathrm{~mm}$ and $111.8 \mathrm{~mm}$. Only the machined hole with the focal length of $56 \mathrm{~mm}$ still has the ultra-small hole at the center. The aspect ratios of machined holes, defined as the ratio of diameter to depth, were measured with these three different lenses and the results are shown in Figure 18. It shows shorter focal length produced holes with higher aspect ratio. Meanwhile, the aspect ratio decreased with the power density. A jump with the focal length of $111.8 \mathrm{~mm}$ might be due to the instability of the laser pulse.

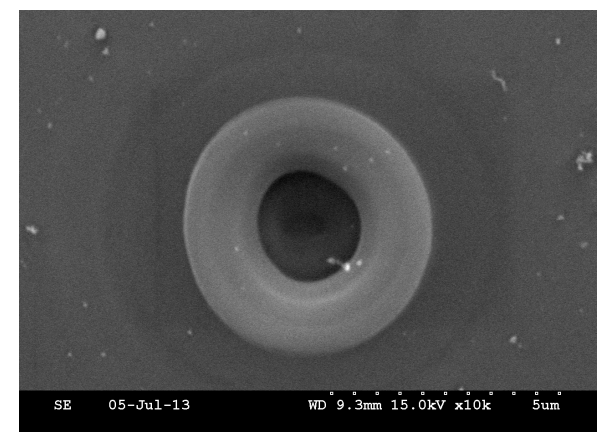

(a) Focal length $=56 \mathrm{~mm}$

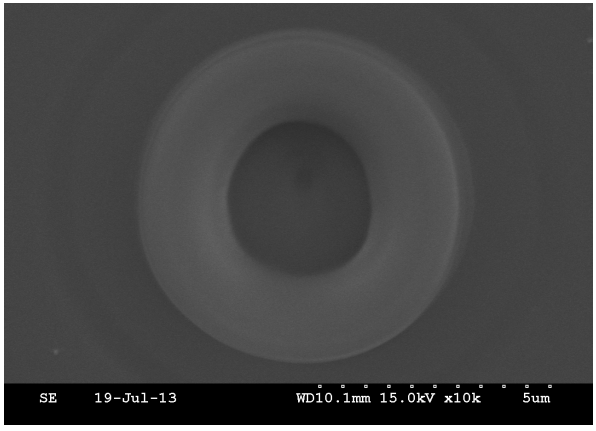

(b) Focal length $=83.8 \mathrm{~mm}$

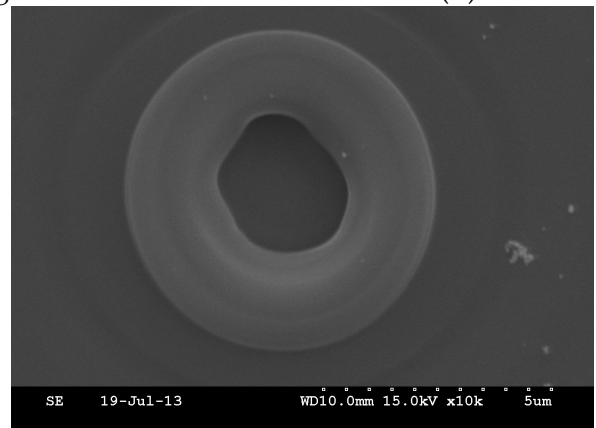

(c) Focal length $=111.8 \mathrm{~mm}$

Figure 17. SEM picture of machined holes with a power density of $1.0 \times 10^{8} \mathrm{~W} / \mathrm{cm}^{2}($ Scale bar $=5 \mu \mathrm{m})$.

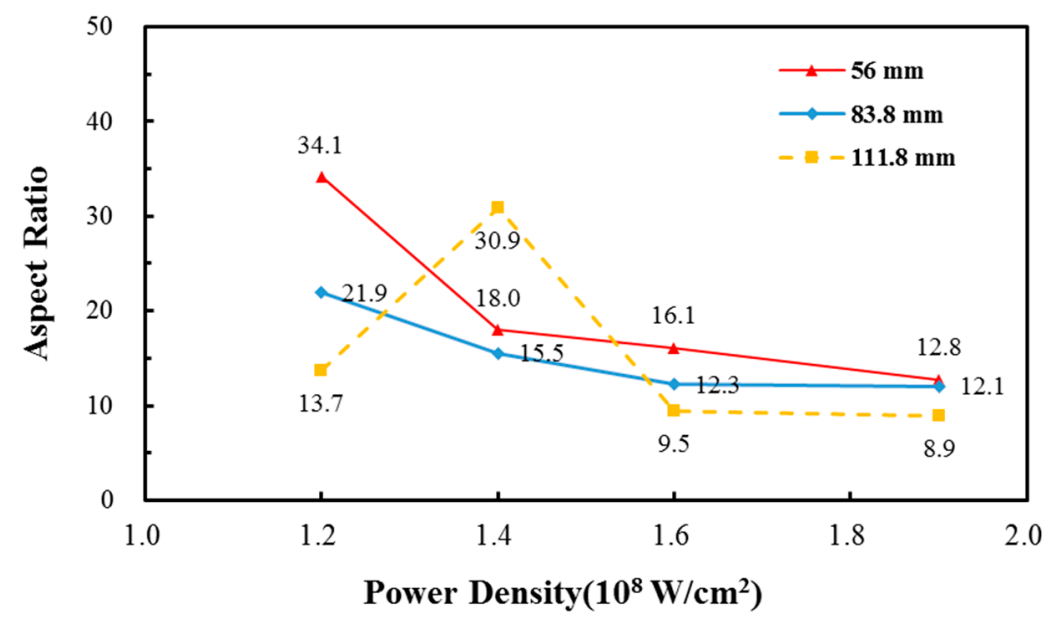

Figure 18. Aspect ratio of holes at different power density with three different focal length.

\section{Conclusions}

In conclusion, we have demonstrated that water droplets can be used to achieve laser direct writing nanofabrication. With a droplet diameter of $\sim 13 \mu \mathrm{m}$, a hole with a diameter of $600 \mathrm{~nm}$ was 
successfully fabricated at a substrate temperature of $12{ }^{\circ} \mathrm{C}$ for $20 \mathrm{~s}$. We also found that the hole diameter is around a third of the water droplet diameter. Therefore, smaller droplets produce smaller holes. The machined holes were not affected much by the focal length of the lens, but a hole with less than $100 \mathrm{~nm}$ in diameter at the center was observed. The aspect ratio decreased with the power density as well as the focal length of the lens. To reduce the power density further, sub-100 nm holes could possibly be fabricated.

Acknowledgments: The authors would like to thank the National Science Council (NSC102-2221-E-224-015-) for their financial support, and Y.C. Lee's Lab in the Department of Mechanical Engineering at National Cheng Kung University, Taiwan, for their equipment in supporting the experiments herein.

Author Contributions: Yuan-Jen Chang conceived and designed the experiments; Chao-Hsuan Chang performed the experiments; Chao-Ching Ho, Jin-Chen Hsu and Chia-Lung Kuo analyzed the data; Yuan-Jen Chang wrote the paper. All authors have read and approved the final manuscript.

Conflicts of Interest: The authors declare no conflict of interest.

\section{References}

1. Forrest, S.R. The path to ubiquitous and low-cost organic electronic applications on plastic. Nature 2004, 428, 911-918. [CrossRef] [PubMed]

2. Sbiaa, R.; Piramanayagam, S.N. Patterned Media Towards Nano-bit Magnetic Recoarding: Fabrication and Challenges. Recent Pat. Nanotech. 2007, 1, 29-40. [CrossRef]

3. Jeans, A.; Almanza-Workman, M.; Cobene, R.; Elder, R.; Garcia, R.; Gomez-Pancorbo, F.; Jackson, W.; Jam, M.; Kim, H.-J.; Kwon, O.; et al. Advanceds in roll-to-roll imprint lithography for display applications. Proc. SPIE 2010, 7637. [CrossRef]

4. Madden, S.; Han, T.; Bulla, D.; Davies, B.L. Low loss chalcogenide glass waveguides fabricated by thermal nanoimprint lithography. In Proceedings of Optical Fiber Communication Conference (OFC), San Diego, CA, USA, 11-15 March 2010; pp. 1-3.

5. Liu, A.; Jones, R.; Liao, L.; Samara-Rubio, D.; Rubin, D.; Cohen, O.; Nicolaescu, R.; Paniccia, M. A high-speed silicon optical modulator based on a metal-oxide-semiconductor capacitor. Nature 2004, 427, 615-618. [CrossRef] [PubMed]

6. Li, L.; Hong, M.; Schmidt, M.; Zhong, M.; Malshe, A.; Huis in'tVeld, B.; Kovalenko, V. Laser nano-manufacturing-State of the art and challenges. CIRP Ann. Manuf. Technol. 2011, 60, 735-755. [CrossRef]

7. Lu, Y.F.; Hu, B.; Mai, Z.H.; Wang, W.J.; Chim, W.K.; Chong, T.C. Laser-scanning probe microscope based nanoprocessing of electronics materials. Jpn. J. Appl. Phys. 2001, 40, 4395-4398. [CrossRef]

8. Murphy-DuBay, N.; Wang, L.; Xu, X. Nanolithography using high transmission nanoscale ridge aperture probe. Appl. Phys. A 2008, 93, 881-884. [CrossRef]

9. Guo, W.; Wang, Z.B.; Li, L.; Whitehead, D.J.; Luk'yanchuk, B.S.; Liu, Z. Near-field laser parallel nanofabrication of arbitrary-shaped patterns. Appl. Phys. Lett. 2007, 90, 243101. [CrossRef]

10. Li, L.; Guo, W.; Wang, Z.B.; Liu, Z.; Whitehead, D.J.; Luk'yanchuk, B.S. Large-area laser nano-texturing with user-defined patterns. J. Micromech. Microeng. 2009, 19, 054002. [CrossRef]

11. McLeod, E.; Arnold, C.B. Subwavelength direct-write nanopatterning using optically trapped microspheres. Nat. Nanotech. 2008, 3, 413-417. [CrossRef] [PubMed]

12. Leitz, K.-H.; Quentin, U.; Alexeev, I.; Schmidt, M. Process investigations of optical trap assisted direct-write microsphere near-field nanostructuring. CIRP Ann. Manf. Technol. 2012, 61, 207-210. [CrossRef]

13. Santbergen, R.; van Zolingen, R.J.C. The absorption factor of crystalline silicon PV cells: A numerical and experimental study. Sol. Energy Mater. Sol. Cells 2008, 92, 432-444. [CrossRef]

14. Pope, R.M.; Fry, E.S. Absorption spectrum $(380-700 \mathrm{~nm})$ of pure water. II. integrating cavity measurements. Appl. Opt. 1997, 36, 8710-8723. [CrossRef] [PubMed]

(C) 2016 by the authors; licensee MDPI, Basel, Switzerland. This article is an open access article distributed under the terms and conditions of the Creative Commons by Attribution (CC-BY) license (http://creativecommons.org/licenses/by/4.0/). 